\title{
AKTIVITAS BERSEPATU RODA SEBAGAI REFLEKSI GAYA HIDUP GENERASI “Z” MASYARAKAT KOTA SEMARANG
}

\author{
Kardiyono $^{1)}$, TjetjepRohendi Rohidi ${ }^{2)}$ \\ PJKR FKIP UNWAHAS \\ pjkrunwahas@gmail.com
}

\begin{abstract}
ABSTRAK
Sepatu roda merupakan salah satu olahraga pilihan masyarakat perkotaan. Tujuan penelitian ini adalah untuk menganalisis aktivitas sepatu roda yang menjadi pilihan generasi " $Z$ " pada masyarakat di Kota Semarang. Penelitian ini menggunakan pendekatan penelitian kualitatif studi kasus. Subyek penelitian adalah warga masyarakat Kota Semarang generasi "Z" yang melakukan aktivitas sepatu roda. Informan pendukung penelitian adalah pelatih dan atlet klub sepatu roda.Teknik analisis data pada menggunakan analisis data model interaktif, terdiri atas komponen reduksi data, penyajian data dan penarikan kesimpulan. Hasil penelitian menunjukkan bahwa sebagian besar masyarakat yang melakukan aktivitas sepatu roda berusia 7-23 tahun atau tergolong dalam generasi "Z". Aktivitas sepatu roda dilakukan di kawasan jalan, trotoar Simpang Lima dan Jl. Pahlawan, track Jatiridi, track Bandara dan track Akademi Kepolisian. Tujuan mereka melakukan aktivitas ini adalah untuk olahraga rekreasi dan menjaga kebugaran tubuh, budaya trend dan mencari prestasi. Aktivitas sepatu roda juga membentuk pranata sosial, pranata ekonomi dan pranata budaya di Kota Semarang. Nilai-nilai yang terkandung dalam aktivitas ini antara lain pantang menyerah, kerjasama, disiplin, tanggungjawab, saling menghormati dan menghargai. Pemerintah Kota Semarang diharapkan lebih mendukung kegiatan ini, fasilitas yang ada agar lebih dijaga dan ditambah yang lebih baik, serta membantu Perserosi dalam kegiatan pelatihan untuk atlet dan pelatih.
\end{abstract}

Kata Kunci: Aktivitas Sepatu Roda, Gaya Hidup, Generasi Z

\begin{abstract}
Roller skates are one of the sport choices of urban society. The purpose of this study is to analyze the activity of roller skates of generation " $Z$ " in the community in the city of Semarang. This research uses a case study qualitative research approach. The research subjects were residents of Semarang City generation "Z" who did roller skate activities. Research informants are trainers and athletes of the roller skate club. Data analysis techniques using interactive model data analysis, consisting of data reduction components, data presentation and conclusion. The results showed that the majority of people who do roller skates aged 7-23 years or belong to the "Z" generation. Rollerblading activities are carried out on the road, Simpang Lima and Jl. Pahlawan, Jatiridi track, Airport track and Police Academy track. Their purpose in carrying out this activity is for recreational sports and maintaining physical fitness, cultural trends and seeking achievement. Roller skates activities also form social, economic and cultural institutions in the Semarang City. The values include unyielding, cooperation, discipline, responsibility, mutual respect and respect. The Semarang City Government must supportive of this activity, the existing facilities to be better, and to assist Perserosi to training for athletes and coaches.

Keywords: Roller Skating Activity, Lifestyle, Generation of Z
\end{abstract}




\section{Aktivitas Bersepatu Roda Sebagai Refleksi Gaya Hidup Generasi “Z” Masyarakat \\ Kota Semarang \\ Oleh : Kardiyono ${ }^{1)}$, TjetjepRohendi Rohidi ${ }^{2)}$}

\section{A. PENDAHULUAN}

Olahraga adalah suatu bentuk kegiatan jasmani yang terdapat di dalam permainan, perlombaan dan kegiatan intensif dalam rangka memperoleh relevansi kemenangan dan prestasi optimal. Atau dengan istilah lain dapat dikatakan bahwa olahraga merupakan serangkaian gerak raga yang teratur dan terencana untuk memelihara gerak (mempertahankan hidup) dan meningkatkan kemampuan gerak (meningkatkan kualitas hidup). Seperti hal nyamakan, Olahraga merupakan kebutuhan hidup yang sifatnya periodic ; artinya Olahraga sebagai alat untuk memelihara dan membina kesehatan, tidak dapat ditinggalkan

Bagi masyarakat perkotaan yang maju dan modern kegiatan olahraga sudah menjadi kebutuhan dalam kehidupan sehari-hari. Olahraga telah dipandang memiliki berbagai fungsi yang tidak hanya untuk mengembangkan kualitas kebugaran jasmani saja, tetapi juga mengembangkan kualitas mental individu dan masyarakat secara lebih utuh dan mantap. Melalui olahraga misalnya, individu dapat mengembangkan segi-segi mental kepribadian, moral, kepemimpinan, kesetiaan, loyalitas, pengabdian, relasi intra dan interpersonal lebih baik lagi. Karena itu, tidak berlebihan kiranya jika dikatakan bahwa, olahraga memberikan pembelajaran dalam membangun budaya keunggulan dalam arti yang luas.

Olahraga sepatu roda menjadi salah satu pilihan masyarakat perkotaan untuk pengembangan kualitas kebugaran jasmani. Olahraga sepatu roda yang sekarang ini memasyarakat di Kota Semarang menjadi olahraga, kecenderungan umum menjadi bagian dari tujuan olahraga pendidikan dan olahraga rekreasi. Olahraga sepatu roda yang pelaksanaannya di sekitar Simpang Lima dengan menggunakan sarana dan prasarana yang ada yaitu trotoar dan jalan di sekitar Simpang Lima menjadi bagian dari kehidupan sehat dalam menjalankan kehidupan sehari-hari masyarakat Kota Semarang.

Kegiatan olahraga sepatu roda melibatkan banyak orang yang saling berinteraksi atau berkomunikasi satu sama lain, yang sekaligus juga menguatkan banyak kepentingan di dalamnya. Dengan kata lain, pada satu sisi menjadi arena yang memadukan dan mengintegrasikan semua kepentingan, kebutuhan, dan 


\section{Aktivitas Bersepatu Roda Sebagai Refleksi Gaya Hidup Generasi “Z” Masyarakat Kota Semarang \\ Oleh : Kardiyono ${ }^{1)}$, TjetjepRohendi Rohidi ${ }^{2)}$}

harapan setiap orang yang terlibat. Dalam arti berfungsi memfasilitasi ekspresi setiap individu atau kelompok. Pada sisi lain berpotensi menjadi sumber pertentangan berbagai orang yang terlibat di dalamnya. Dari segi ini, olahraga bukan hanya dapat memberikan sumbangan positif bagi kehidupan, tetapi juga mengandung potensi negatif yang harus dicegah.

Kurangnya melakukan aktifitas gerak dapat berdampak buruk bagi kesehatan, salah satunya akan mengalami penyakit hipokinetik (penyakit kurang gerak), dan penyakit ini juga akan menyebabkan timbulnya peningkatan penyakit degeneratif, seperti penyakit jantung koroner, stroke, tekanan darah tinggi, kencing manis dan lain-lain.

Anne Ahira (2012:17) menyatakan bahwa "konsep dari sepatu roda adalah meluncur dengan cepat diatas sepatu roda dan adanya rasa sensasi yang menyenangkan diatas jalan yang keras”. Disebutkan juga bahwa dalam sepatu roda selain adanya sensasi ada juga unsur kebugaran jasmani.

Alexander Bont (2012:62) menyatakan bahwa meluncur dengan cepat merupakan penerapan gaya geser terhadap cabang olahraga sepatu roda agar dapat melaju dengan cepat yaitu: mengubah kecepatan dengan menambah kecepatan arah gerak, dimana atlet harus mengetahui arah seperti waktu belok atau saat keadaan lurus. Mencondongkan badan agar tekanan angin tidak menghambat gerak laju untuk menambah kecepatan, apabila badan tidak condong kedepan angin akan tertahan oleh badan dan tidak dapat melaju dengan cepat atau maksimal. Kekuatan otot-otot untuk menyeimbangkan badan untuk berdiri di sepatu roda. Kecepatan meluncur diatas sepatu roda dan pencapaian kebugaran dalam bersepatu roda dibutuhkan suatu kondisi fisik yang baik.

Yuyun (2012:88) menyatakan bahwa kondisi fisik merupakan unsur yang sangat penting hampir diseluruh cabang olahraga. Aktivitas fisik adalah setiap gerakan tubuh yang dihasilkan oleh otot rangka yang memerlukan pengeluaran energi. Aktivitas fisik yang tidak ada (kurangnya aktivitas fisik) merupakan faktor risiko independen untuk penyakit kronis, dan secara keseluruhan diperkirakan menyebabkan kematian secara global. Aktivitas fisik secara teratur memiliki efek yang menguntungkan terhadap kesehatan yaitu: terhindar dari penyakit jantung, 


\section{Aktivitas Bersepatu Roda Sebagai Refleksi Gaya Hidup Generasi “Z” Masyarakat Kota Semarang \\ Oleh : Kardiyono ${ }^{1)}$, TjetjepRohendi Rohidi ${ }^{2)}$}

stroke, osteoporosis, kanker, tekanan darah tinggi, kencing manis, dan lain-lain. Berat badan terkendali, otot lebih lentur dan tulang lebih kuat, bentuk tubuh menjadi ideal dan proporsional, lebih percaya diri, lebih bertenaga dan bugar.

Ada 3 tipe atau macam sifat aktivitas fisik yang dapat kita lakukan untuk mempertahankan kesehatan tubuh yaitu:

1) Ketahanan (endurance)

Aktivitas fisik yang bersifat untuk ketahanan, dapat membantu jantung, paruparu, otot, dan sistem sirkulasi darah tetap sehat dan membuat kita lebih bertenaga. Untuk mendapatkan ketahanan maka aktivitas fisik yang dilakukan selama 30 menit (4-7 hari per minggu).

Contoh beberapa kegiatan yang dapat dipilih seperti: berjalan kaki, misalnya turunlah dari bus lebih awal menuju tempat kerja kira-kira menghabiskan 20 menit berjalan kaki dan saat pulang berhenti di halte yang menghabiskan 10 menit berjalan kaki menuju rumah lari ringan, berenang,senam,bermain tenis.

2) Kelenturan (flexibility)

Aktivitas fisik yang bersifat untuk kelenturan dapat membantu pergerakan lebih mudah, mempertahankan otot tubuh tetap lemas (lentur) dan sendi berfungsi dengan baik. Untuk mendapatkan kelenturan maka aktivitas fisik yang dilakukan selama 30 menit (4-7 hari per minggu).

Contoh beberapa kegiatan yang dapat dipilih seperti: peregangan, mulai dengan perlahan-lahan tanpa kekuatan atau sentakan, lakukan secara teratur untuk 10-30 detik, bisa mulai dari tangan dan kaki, Senam taichi, yoga.

3) Kekuatan (strength)

Aktifitas fisik yang bersifat untuk kekuatan dapat membantu kerja otot tubuh dalam menahan sesuatu beban yang diterima, tulang tetap kuat, dan mempertahankan bentuk tubuh serta membantu meningkatkan pencegahan terhadap penyakit seperti osteoporosis. Untuk mendapatkan kelenturan maka aktivitas fisik yang dilakukan selama 30 menit (2-4 hari per minggu). Contoh beberapa kegiatan yang dapat dipilih seperti: Push-up, pelajari teknik yang benar untuk mencegah otot dan sendi dari kecelakaan, naik turun tangga, angkat berat/beban, mengikuti kelas senam terstruktur dan terukur (fitness). 


\section{Aktivitas Bersepatu Roda Sebagai Refleksi Gaya Hidup Generasi “Z” Masyarakat Kota Semarang \\ Oleh : Kardiyono ${ }^{1)}$, TjetjepRohendi Rohidi ${ }^{2)}$}

Masyarakat adalah sekumpulan manusia yang secara relative mandiri, yang hidup bersama-sama yang cukup lama, yang mendiami suatu wilayah tertentu, memiliki kebudayaan yang sama dan melakukan sebagian besar kegiatan dalam kelompok itu (Paul B. Harton). Sedangkan menurut Abdul Syani, masyarakat adalah berkumpul, bersama, hidup bersama dengan saling berhubungan dan saling mempengaruhi.

Wirt mengatakan bahwa kota adalah suatu pemilihan yang cukup besar, padat dan permanen, dihuni oleh orang-orang yang heterogen kedudukan sosialnya. Sedangkan menurut Weber, apabila penghuni setempatnya dapat memenuhi sebagian besar kebutuhan ekonominya dipasar lokal.

Beberapa ciri yang menonjol pada masyarakat perkotaan, yaitu: 1) Kehidupan keagamaannya berkurang, kadangkala tidak terlalu dipikirkan karena memang kehidupan yang cenderung kearah keduniaan saja; 2) Orang kota pada umumnya dapat mengurus dirinya sendiri tanpa harus bergantung pada orang lain (Individualisme) ; 3) Pembagian kerja diantara warga-warga kota juga lebih tegas dan mempunyai batas-batas yang nyata; 4) Kemungkinan-kemungkinan untuk mendapatkan pekerjaan juga lebih banyak diperoleh warga kota; 5) Jalan kehidupan yang cepat dikota-kota, mengakibatkan pentingnya factor waktu bagi warga kota, sehingga pembagian waktu yang teliti sangat penting, untuk dapat mengejar kebutuhan-kebutuhan seorang individu ; dan 6) Perubahan-perubahan tampak nyata dikota-kota, sebab kota-kota biasanya terbuka dalam menerima pengaruh-pengaruh dari luar.

Gaya hidup adalah perilaku seseorang yang ditunjukkan dalam aktivitas, minat dan opini khususnya yang berkaitan dengan citra diri untuk merefleksikan status sosialnya. Gaya hidup merupakan frame of reference yang dipakai sesorang dalam bertingkah laku dan konsekuensinya akan membentuk pola perilaku tertentu (Awan: 2009). Sedangkan menurut Lisnawati (2001) gaya hidup sehat menggambarkan pola perilaku sehari-hari yang mengarah pada upaya memelihara kondisi fisikfisik, mental dan social berada dalam keadaan positif. Gaya hidup sehat meliputi kebiasaan tidur, makan, pengendalian berat badan, tidak merokok 


\section{Aktivitas Bersepatu Roda Sebagai Refleksi Gaya Hidup Generasi “Z” Masyarakat Kota Semarang \\ Oleh : Kardiyono ${ }^{1)}$, TjetjepRohendi Rohidi ${ }^{2)}$}

atau minum-minuman beralkohol, berolahraga secara teratur dan terampil dalam mengelola stres yang dialami. Sejalan dengan pendapat Lisnawati, Noto Atmojo (2005) menyebutkan bahwa perilaku sehat (healthy behavior) adalah perilakuperilaku atau kegiatan-kegiatan yang berkaitan dengan upaya mempertahankan dan meningkatkan kesehatan.

Kualitas hidup yang sekarang ini cenderung mencerminkan suatu gaya hidup yang dijalankan. Gaya hidup modern sebenarnya merupakan sebuah life style (gaya hidup) yang mengikuti pola perkembangan zaman, dengan segala bentuk kemajuan iptek. Gaya hidup bukanlah suatu hal yang baru atau yang aneh lagi dalam kehidupan manusia itu sendiri. Perkembangan dan perubahan tidak dapat dibendung oleh apapun. Ini yang terjadi dalam peradaban manusia. Dari kehidupan yang paling primitive, manusia telah mengalami perkembangan yang luar biasa yang mengarah pada sebuah bentuk gaya hidup modern. Hal ini tentu tak dapat dihindari. Manusia tidak dapat melarikan diri dari segala bentuk kemajuan iptek. Manusia pada dasarnya dituntut untuk mampu beradaptasi terhadap siapa saja, dimana saja, kapan saja dan dalam kondisi apapun termasuk kemajuan iptek.

Konsep gaya hidup modern sudah ada dan akan terus mengalami perubahan dan perkembangan dalam berbagai bentuk. Pada umumnya, para pakar sepakat bahwa cirri utama yang melatarbelakangi sistem atau model apapun dari suatu masyarakat modern adalah derajat rasionalitas (berkaitan dengan tingkatan pikiran manusia) yang tinggi. Artinya, kegiatan-kegiatan dalam masyarakat modern terselenggara berdasarkan nilai-nilai dan dalam pola-pola yang objektif serta efektif. Dengan kata lain, iptek adalah kekuatan pendorong bagi sebuah proses transformasi.

\section{B. METODE}

Penelitian ini menggunakan pendekatan penelitian kualitatif dengan design studi kasus. Studi kasus adalah spesifikasi kasus dalam suatu kejadian baik itu yang mencakup individu, kelompok budaya ataupun suatu potret kehidupan. 


\section{Aktivitas Bersepatu Roda Sebagai Refleksi Gaya Hidup Generasi “Z” Masyarakat Kota Semarang \\ Oleh : Kardiyono ${ }^{1)}$, TjetjepRohendi Rohidi ${ }^{2)}$}

Penelitian ini difokuskan kepada pelaksanaan aktivitas sepatu roda di Kota Semarang. Subjek dalam penelitian ini adalah warga masyarakat yang berusia antara 7-23 tahun atau biasa disebut generasi “Z” yang melakukan aktivitas fisik sepatu roda, pedagang yang menyewakan sepatu roda sebagai informan kunci dan perkumpulan sepatu roda sebagai informan pendukung.Data yang sebagian besar berbentuk deskripsi dan diperoleh dari tiga sumber yaitu peristiwa, pelaku,dan dokumen. Teknik pengumpulan data yang digunakan dalam penelitian ini adalah pengamatan, wawancara, dokumentasi dan perekaman visual atas data peristiwa.Teknik analisis data pada penelitian ini menggunakan analisis data model interaktif yaitu yang terdiri atas komponen reduksi data, penyajian data, dan penarikan kesimpulan atau verifikasi data.

\section{HASIL DAN PEMBAHASAN}

Olahraga sebagai suatu kebutuhan bagi masyarakat yang pemenuhan berpedoman pada kebudayaannya; yang di dalamnya terjalin berbagai aspek budaya yang jalin-menjalin dalam suatu cara berpikir yang dapat diterima akal pikiran, moral, masyarakat. Aktivitas sepatu roda menjadi salah satu kegiatan pilihan remaja Kota Semarang untuk mengaktualisasikan diri dengan berbagai tujuan, antara lain untuk kebugaran dan mengisi waktu luang.

Kegiatan bersepatu roda dilakukan hampir setiap hari mulai sore sampai malam, bahkan pada hari sabtu sampai larut malam bahkan sampai minggu pagi. Masyarakat yang melakukan aktivitas olahraga sepatu roda berkumpul dan bermain sepatu roda berkeliling di Simpang Lima Kota Semarang. Mereka datang dengan perorangan atau bersama kelompoknya. Mereka biasa menyewa sepatu roda di sekitar kawasan Simpang Lima yang saat ini menjadi komoditi yang lumayan menambah pundi-pundi rejeki bagi para pedagang persewaan sepatu roda, meskipun sebagian besar sudah punya sepatu roda sendiri.

Aktivitas sepatu roda yang dilakukan di trotoar bunderan Simpang Lima, Kota Semarang, Jawa Tengah. Kegiatan ini menjadi ajang bermain anak-anak dan remaja. Aktivitas sepatu roda merambat sampai ke jalan-jalan sekitar Simpang Lima hingga ke trotoar Jalan Pahlawan. Bahkan, sejumlah anak yang sudah mahir 


\section{Aktivitas Bersepatu Roda Sebagai Refleksi Gaya Hidup Generasi “Z” Masyarakat Kota Semarang \\ Oleh : Kardiyono ${ }^{1)}$, TjetjepRohendi Rohidi ${ }^{2)}$}

bermain sepatu roda sering memilih lokasi di trotoar depan Masjid Baiturrahman, Semarang. Adapun anak-anak yang baru belajar bermain sepatu roda membuat arena di berbagai titik trotoar Simpang Lima Kota Semarang, antara lain di trotoar depan Hotel Ciputra dan di trotoar tembusan dari arah Jalan Pandanaran Kota Semarang. Aktivitas sepatu roda ini juga membawa dampak terhadap perekonomian warga masyarakat sekitar. Sebagai contoh Ibu Dewi, beliau bias mendapatkan tambahan pundi-pundi rupiah dengan berjualan makanan ringan dan minuman untuk memenuhi kebutuhan para pelaku aktivitas sepatu roda di Simpang Lima. Begitu juga dengan mas Koko, salah satu pedagang dan penyewa sepatu roda di Simpang Lima.

Perkembangan sepatu roda di kota Semarang sedang mengalami peningkatan, animo masyarakat kota semarang akan permainan ini meningkat tapukul. Peningkatan popularitasnya ini dapat dilihat dengan adanya peminat sepatu roda di Simpang Lima setiap harinya. Hal ini juga diikuti dengan maraknya para pemilik sepatu roda yang menyewakan sepatu roda kepada pengunjung. Permainan sepatu roda mulai banyak kita jumpai di kawasan pusat kota setiap harinya.

Meningkatnya animo masyarakat akan olahraga ini seharusnya dapat dimanfaatkan oleh PORSEROSI sebagai alat untuk menjaring bibit- bibit calon atlet sepatu roda kota Semarang dengan mengarahkannya tergabung ke dalam salah satu klub sepatu roda. Namun, hingga saat ini keberadaan klub-klub sepatu roda di bawah naungan PORSEROSI kota Semarang masih belum banyak diketahui oleh masyarakat kota Semarang. Sehingga, para penggemar sepatu roda belum terarahkan bakatnya.

Ibu kota Jawa Tengah, kota Semarang merupakan tempat lahirnya para atlet Sepatu roda. Prestasi yang ditunjukkan atlet Kota Semarangpun cukup menjanjikan. Bahkan, di event internasional pun para atlet sepatu roda mampu bersaing dengan atlet manca negara dan mampu memberikan hasil yang memuaskan.Ada 2 klub sepatu roda yang masih akti fdalam melakukan latihan dan pembinaan, yaitu klub Kairos (Kahuripan Roller Sport) dan klub Ikos (Ikatan 


\section{Aktivitas Bersepatu Roda Sebagai Refleksi Gaya Hidup Generasi “Z” Masyarakat Kota Semarang \\ Oleh : Kardiyono ${ }^{1)}$, TjetjepRohendi Rohidi ${ }^{2)}$}

Orang Tua Atlet Sepatu Roda). Kedua klub sepatu roda ini banyak melahirkan atlet-atlet yang berprestasi, baik di event regional ataupun nasional.

Setiap kegiatan olahraga mempunyai peraturan dan tata tertib dalam latihan sebagai wujud pranata kehidupan klub-klub olahraga. Di dalam klub-klub sepatu roda di Kota Semarang pranata itu tercermin dalam aktivitas yang dilakukan dalam setiap latihan. Aktivitas yang dilakukan klub tercermin dari program latihan yang dilakukan. Masing-masing klub sepatu roda memiliki program latihan masing-masing, berbeda antara klub satu dengan yang lainnya, akan tetapi tujuan dari program latihan sama yaitu pencapaian prestasi semaksimal mungkin dan pemassalan kepada masyarakat. Pelaksanaan program latihan yang mengarah pada pencapaian prestasi dan pemassalan tersebut dilakukan secara berkesinambungan serta berlangsung rutin dan terstruktur. Dengan demikian, dapat disimpulkan bahwa peserta aktivitas sepatu roda, khususnya anak-anak yang latihan di klub sepatu roda di Kota Semarang dalam kondisi latihan yang terprogram dengan pola-pola latihan yang mengarah pada pencapaian prestasi. Pelaksanaan program latihan yang terjadi pada lingkungan klub tersebuttersirat dalam konteks sosialisasi dan pola-pola latihan di klub sepatu roda di Kota Semarang.

Car free day di Simpang Lima selain digunakan untuk latihan sepatu roda yang mengarah pada prestasi, juga digunakan untuk sepatu roda gaya bebas atau free style. Menurut pelatih Genesis dan sekaligus pendiri klub sepatu roda free style (saat ini sudah tidak aktif latihan) sangat senang sekali adanya tempat yang dapat digunakan untuk melatih. Ia mengatakan bahwa bermain sepatu roda bisa menggunakan tempat yang lapangannya tidak begitu luas. Latihan yang dilakukan adalah dengan zig-zag dengan berputar yang memerlukan keterampilan yang lebih. Klub kami berdiri baru satu tahun yang sekarang sudah beranggotakan sekitar 80 an. Anak-anak sudah banyak yang tahu dan terbiasa kalau saat acara car free day di Simpang Lima mereka akan berkumpul dan bermain sepatu roda.

Kedua pelatih mempunyai komentar yang sama, bahwa acara Car free Day di kawasan Simpang Lima dan Jalan Pahlawan Kota Semarang merupakan salah satu wujud kebiasaan dari sebagian masyarakat Kota Semarang, khususnya 


\section{Aktivitas Bersepatu Roda Sebagai Refleksi Gaya Hidup Generasi “Z” Masyarakat Kota Semarang \\ Oleh : Kardiyono ${ }^{1)}$, TjetjepRohendi Rohidi ${ }^{2)}$}

generasi anak muda yang gemar atau hobi melakukan aktivitas olahraga sepatu roda.

Tujuan pelaku melakukan aktivitas sepatu roda beragam. Ada yang sekedar hoby, coba-coba atau mencari sensasi, ada yang untuk menurunkan berat badan atau menjaga kebugaran tubuh, ada yang ingin otot-ototnya bertambah besar, ada yang berolahraga untuk bermain, ada untuk memulihkan kondisi tubuhnya karna sakit, mengisi waktu luang, ada yang berolahraga karena merupakan salah satu mata pelajaran disekolahnya, dan sebagainya.

Aktivitas sepatu roda yang dilakukan generasi “Z” di Simpang Lima Kota Semarang mempunyai banyak nilai-nilai olahraga, seperti disiplin, kerjasama, tanggungjawab, pantang menyerah, dan lain-lain

\section{SIMPULAN}

Simpulan dari hasil analisis data penelitian aktivitas sepatu roda sebagai releksi gaya hidup generasi "Z" masyarakat Kota Semarang, adalah sebagai berikut.

1) Aktivitas sepatu roda menjadi pilihan bagi masyarakat Kota Semarang khususnya Generasi "Z” (usia 7-23 tahun) dengan tujuan dengan tujuan untuk olahraga kebugaran dan kesehatan tubuh, olahraga rekreasi dan olahraga meraih prestasi.

2) Aktivitas sepatu roda membentuk pranata sosial, pranata ekonomi dan pranata budaya di Kota Semarang.

3) Orientasi nilai-nilai yang mendorong warga masyarakat pelakuaktivitas sepatu roda antara lain terbentuknya rasa hormat, tanggungjawab, kerjasama, peduli, jujur, dan adil sertamenjadi masyarakat yang peduli dengan budaya olahraga, khususnya di Kota Semarang.

\section{DAFTAR RUJUKAN}

Anne Ahira. 2010. Sepatu Roda. Bandung: Rosada. 
Aktivitas Bersepatu Roda Sebagai Refleksi Gaya Hidup Generasi “Z” Masyarakat

Kota Semarang

Oleh : Kardiyono ${ }^{1)}$, TjetjepRohendi Rohidi ${ }^{2)}$

Anselm Strauss, Juliet Corbin. 2009. Jogjakarta: Basics of Qualitative Research: Dasar-dasar Penelitian Kualitatif: Terjemahan, Pustaka Pelajar.

Ardiwinata, A. A, Suherman. Dinata, Marta. 2006. Kumpulan Permainan Rakyat.Olahraga Tradisional. Jakarta.

Conny, M. Djunaidi, Almansur Fausan. 2012. Metodologi Penelitian Kualitatif. Jogjakarta. Ar-ruzz Media.

Creswell, JohnW. 2007. Qualitative Inquiry and Research Design. London: Sage Publication Inc.

Departemen Pendidikan dan Kebudayaan Direktorat Jendral Kebudayaan. 1988. Permainan Tradisional Indonesia. Jakarta. Direktorat Permuseuman.

Depdiknas, 2000. Pedoman dan Modul Pelatihan Kesehatan Olahraga Bagi Pelatih Olahragawan Pelajar: Jakarta. Pusat Pengembangan Kualitas Jasmani.

Ekadjati, Edi S, Drs. 2005. Kebudayaan Sunda. Jakarta, Pustaka Jaya.

Emzir. 2012. Metodologi Penelitian Kualitatif. ANALISIS DATA: Jakarta. Rajawali Press.

Evan S. Blog. 2009. "Memanfaatkan Sistem Sebagai Parameter Keberhasilan Adaptasi” dalam: http:blog.its.al.id/Freax.

FORMI. 2011. Makalah Seminar Olahraga Rekreasi Masyarakat. Semarang. Panetia Seminar Olahraga Rekreasi Masyarakat.

Giriwijoyo. 2012. Olahraga Kesehatan. Bandung: PT Remaja.

Hutapea Albert. 2009. Menuju Gaya HidupSehat. Jakarta, Pustaka Utama.

Ilminaida. 2012. Sosiologi (KemajemukandalamMasyarakat). Wordpress.com

Joesoef R. 2012. Konsep Olahraga dalam Kesehatan. Bandung: PT Pustaka.

Kemnegpora. 2007. Undang-Undang Republik Indonesia Nomor 3 Tahun 2005 Tentang Sistem Keolahragaan Nasional: Jakarta. Biro Humas dan Hukum Kementrian Negara Pemuda dan Olahraga RI.

Kemnegpora. 2011. Panduan Sentra Olahraga Rekreasi: Makalah. Jakarta. UNJ.

Koentjoroningrat. 2009. Pengantar Ilmu Antropologi. Jakarta. Rineka Cipta. 
Aktivitas Bersepatu Roda Sebagai Refleksi Gaya Hidup Generasi “Z” Masyarakat

Kota Semarang

Oleh : Kardiyono ${ }^{1)}$, TjetjepRohendi Rohidi ${ }^{2)}$

Maksum, A. 2007. Psikologi Olahraga: Teori dan Aplikasi. Surabaya: Fakultas Ilmu Keolahragaan Universitas Negeri Surabaya.

Mila Anggraini. 2012. Gaya Hidup Orang Kota. Jakarta.

Murni, M. Saputra. M.Y. 2008. Pendidikan Rekreasi: Jakarta. Depdiknas. Dirjen Dikdasmen.

Mutakin Anwar. 2006. Individu, Masyarakat dan Perubahan Sosial. Bandung: Rosada.

Pemerintah Kota Semarang. 2015. Informasi Umum Kota Semarang. (sumber: http://semarangkota.go.id)

Pontjopoetro, S. Dkk 2002. Permainan Anak, Tradisional dan Aktivitas Ritmik. (Modul). Jakarta. Pusat Penerbitan UT.

Pratowo Andi. 2012. Metode Penelitian Kualitatif dalam Perspektif Rancangan Penelitian: Jogjakarta. AR RUZZ MEDIA.

Rafick, M. 2012. Ilmu Sosial \& Budaya Dasar: Jogjakarta. ASWAJA PRESSINDO.

Rohidi, T.R. 2000. Ekspresi Seni Orang Miskin, Adaptasi Simbolik Terhadap Kemiskinan: Bandung. Penerbit Nuansa Yayasan Nuansa Cendekia.

Rohidi, T.R. 2007. Analisis Data Kualitatif. Terjemahan: Buku Sumber Tentang Metode-Metode Baru. Jakarta. UI-Press.

Rohidi, T.R. 2011. Metodologi Penelitian: Semarang. Penerbit Cipta Prima Nusantara CV.

Sofie Medina. 2010. Belajar Sepatu Roda Dijamin Mudah. PT Nasional Yunior Sportindo Media. (http://nysnmedia.com/belajar-sepatu-roda-dijaminmudah-asal-mengikuti-5-tips-sederhana-ini/)

Yuyun Yudiana. 2012. Latihan Fisik. Bandung: UPI Press.

Biodata Penulis :

Nama

: Kardiyono $^{1)}$, TjetjepRohendi Rohidi ${ }^{2)}$

Kantor

: PJKR FKIP UNWAHAS 